\title{
2 Role and Reference Grammar
}

\subsection{Introduction}

Role and Reference Grammar (Foley \& Valin 1984, Van Valin \& LaPolla 1997, Van Valin 2005) is a functionalist grammatical framework which is monostratal in nature. Its ongoing development is driven by two major questions (Foley \& Van Valin 1984, Van Valin 2005: 1): 1) What would a theory of language look like if it were not based on the analysis of English but rather on the analysis of typologically diverse languages such as Lakhota, Tagalog and Dyirbal? and 2) How can the interaction of the syntax, semantics and pragmatics in different languages with differing systems best be captured and explained?

The main focus of work in RRG lies on syntax-semantics interface and pragmatics (Van Valin \& LaPolla 1997, Van Valin 2005), although advances are being made in the area of morphology (e.g. Martín Arista 2008, 2009, 2011, 2012 and Nolan 2010, 2011). Most RRG work is synchronic in nature (including this dissertation), although there is some diachronic work available (e.g. Matasović 2004, Martín Arista 2011). This chapter is intended to serve as an overview of RRG in its present-day conception.

\subsection{Fundamentals}

Apart from the research questions above, RRG holds a number of fundamental insights that make it quite distinct from other theories. Van Valin (2005: 3) points out that any theory of clause structure must meet two fundamental requirements, as displayed in (1). 
(1) a. A theory of clause structure should capture all of the universal features of clauses without imposing features on languages in which there is no evidence or them.

b. A theory should always represent comparable structures in different languages in comparable ways.

In addition to these requirements, RRG rejects any kind of underlying deep structure syntactic representation or transformation commonly found in the generative tradition, Relational Grammar and certain varieties of Case Grammar. RRG's structures can be considered to be flat and the syntactic representation of a given clause reflects its actually occurring form very closely (Van Valin 2005: 3-4).

In general, RRG posits a semantic base which is linked into the syntax using a system known as the linking algorithm (Van Valin 2005: 1-2). Discourse pragmatics - or information structure - influences the whole system and can be described as 'mediating' the linking (Van Valin 2005: $1-2)$. Information structure operates in all aspects of the grammar. Each of the components of RRG has its own representation. These will be discussed in more depth in the following sections. The organization of RRG is visualized in the figure below (Van Valin 2005: 2):

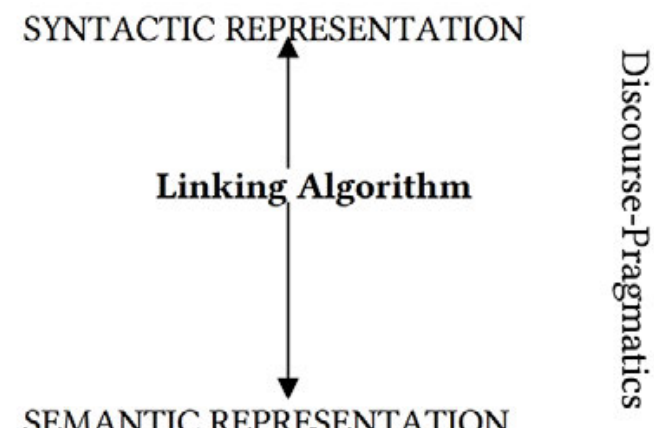

SEMANTIC REPRESENTATION

Figure 1: General organization of RRG.

Central to RRG's conception of non-relational clause structure is the Layered Structure of the Clause or LSC (Van Valin 2005: 3-4). It is based 
on two distinctions; one is made between the predicate and elements that do not predicate. Another (within the class of non-predicating elements) is made between arguments and non-arguments. These distinctions result in units that are defined semantically rather than syntactically (Van Valin 2005: 5). Each of the semantic units has a syntactic equivalent, for which they are the motivating elements:

\begin{tabular}{|l|l|}
\hline Semantic Element(s) & Syntactic Unit \\
\hline Predicate & Nucleus \\
\hline $\begin{array}{l}\text { Argument in semantic } \\
\text { representation of predicate }\end{array}$ & Core argument \\
\hline Non-arguments & Periphery \\
\hline Predicate + Arguments & Core \\
\hline $\begin{array}{l}\text { Predicate + Arguments + Non- } \\
\text { arguments }\end{array}$ & Clause (=Core + Periphery) \\
\hline
\end{tabular}

Table 1: Semantic units underlying the syntactic units of the Layered Structure of the Clause (Van Valin 2005: 5).

It stands out that contrary to other theories, there is no syntactic unit called verb phrase. RRG treats VPs in languages that have them as grammaticalized focus structure patterns (Van Valin 2005: 8 \& 80-81). This means that from the RRG perspective, VP is not a universal constituent and thus it is not listed as a syntactic unit.

Contrary to other theories, Role and Reference Grammar is represented through three different structures or 'projections': a constituent projection (representing the syntactic structure), an operator projection and an information structure projection. Not all of these projections need to be construed in every analysis or visualization. Indeed, representing all three simultaneously comes with certain difficulties as the result is a three-dimensional figure ${ }^{1}$. As the information structure projection is not relevant for the topic of this thesis, it is not discussed in this chapter. The operator and constituent projections will be discussed in the

$\overline{1}$ See Van Valin (2005: 80) for an example of such a figure. 
following sections. For more background on information structure and its projection, see Van Valin (2005).

It is important to point out that Van Valin (2008) argued for replacing the concept of the noun phrase with the concept of reference phrase or RP. Van Valin points out that language is used to refer and predicate (Van Valin 2005: 1). Calling an 'NP' a reference phrase is a logical consequence of this point of view, as RPs are indeed referring expressions (Van Valin 2005: 28) and as such refer to real world participants. They are also categorically varied. That is to say, just like predicates need not be verbs (although they canonically are), RPs are usually headed by nouns but do not need to be (Van Valin 2005: 28). Consider (Van Valin 2008: 167) the German nominative phrase Der Lange ('The tall one') in Der Lange ist eingeschlafen ('The tall one has fallen asleep'). In German, it is undeniably headed by an adjective, whereas the English equivalent has the nominal 'one' as a head. RP has become the standard unit in RRG in post 2008-work. Consequently, in this thesis $R P$ is used in all RRGanalyses. In the discussion of other frameworks, the labels and terminology of the respective approach will be respected.

\subsection{Overall organization of Role and Reference Grammar}

Role and Reference Grammar can be described as a semantically driven syntactic theory. RRG assumes that every verb belongs to a certain aktionsart class. These classes are largely drawn from Vendler's classes $(1957,1967)$ but there are also several non-Vendlerian aktionsart classes in RRG. Each class is paired with a so-called logical structure, which reflects the syntactically relevant elements. These logical structures are based on Dowty's (1979) system of lexical decomposition. A logical structure (or: $L S$ ) is thus a decomposition of certain predicate (including argument slots). Such decompositions constitute the basis for the linking algorithm. The logical structures are not usually depicted together with any of the projections. An exception is when the workings of the linking algorithm are graphically illustrated (see section 2.5.3 and chapter 8). 
The logical structures are stored in the mental lexicon (Van Valin 2005: $47 \&$ 130ff.). Parallel to the mental lexicon, the syntactic inventory is a syntactic equivalent in that it stores the syntactic structures available in a given language (Van Valin 2005: 13-15). As the logical structures (and aktionsarten) play a vital role in the workings of RRG, they are the principle topic of section 2.4. The following sections will focus on the projections and their respective components, explore the semantic basis of RRG (which will play a pivotal role in this dissertation) and finally discuss the linking algorithm. As RRG is an elaborate theory, not all aspects of it will or can be discussed in this chapter.

\subsubsection{Constituent Projection}

The constituent projection is the representation of the syntactic structure in RRG. The concept of the Layered Structure of the Clause is crucial here. The units posited by Van Valin (2005: 4-5) are directly reflected in the constituent projection and form the backbone of syntactic representation: The nucleus is the syntactic unit that contains the predicate (Van Valin 2005: 4-5). The core consists of the nucleus and the arguments of the predicate. Consider the following example from English.

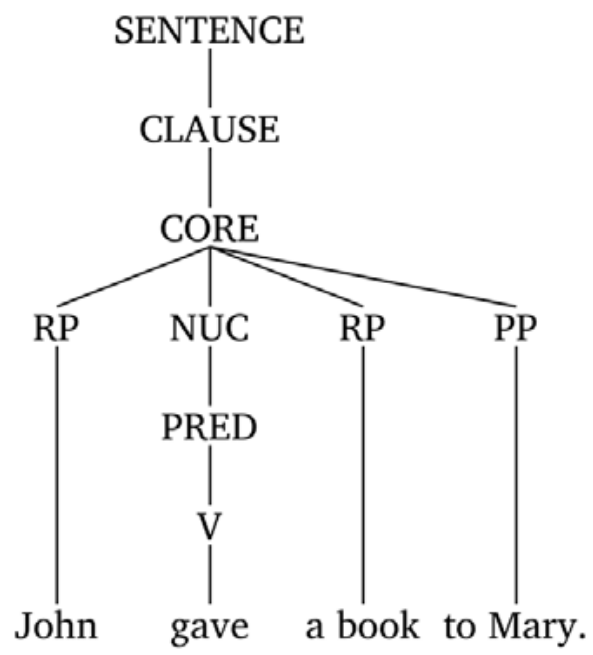

Figure 2: Constituent projection of a simple English sentence. 
The clause is the core and periphery (which contains non-arguments) combined. The highest level in the LSC is the sentence:

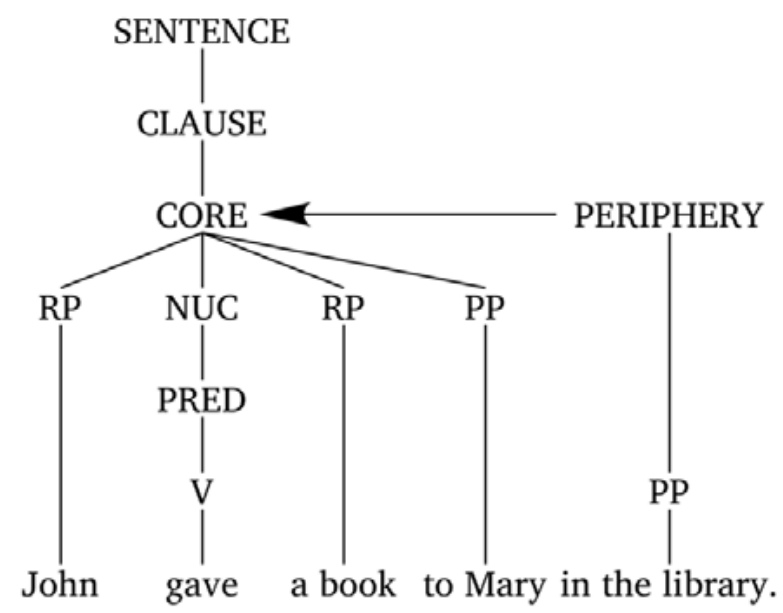

Figure 3: Constituent projection including the periphery.

In addition to these semantically motivated units, there are also pragmatically motivated units. Languages can have an extra-core slot (pre- or postcore slot) and a detached position (left- or a right-detached position). The former contains fronted elements and question words in languages where they do not appear in situ (Van Valin 2005: 5). In the Dutch sentence BIER drinkt hij niet graag' ('BEER he doesn't like to drink'), the fronted object-RP is located in the precore slot (PrCS).

2 'The Dutch adverbial graag roughly translates as gladly or happily. In English, this is expressed by the verb like. 


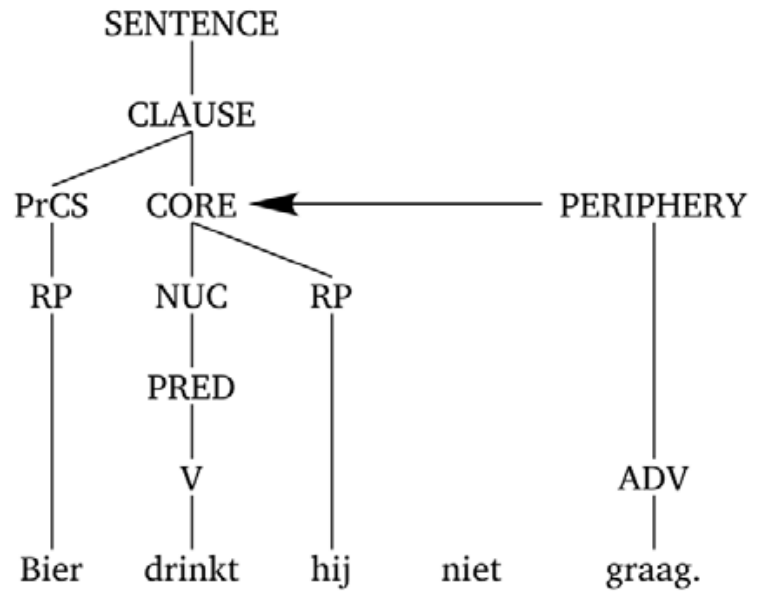

Figure 4: Dutch sentence with a PrCS.

The detached positions (LDP and RDP) are often the location of adverbials that are set off from the rest of the sentence by an intonation break (Van Valin 2005: 5-6). Consider the following example.

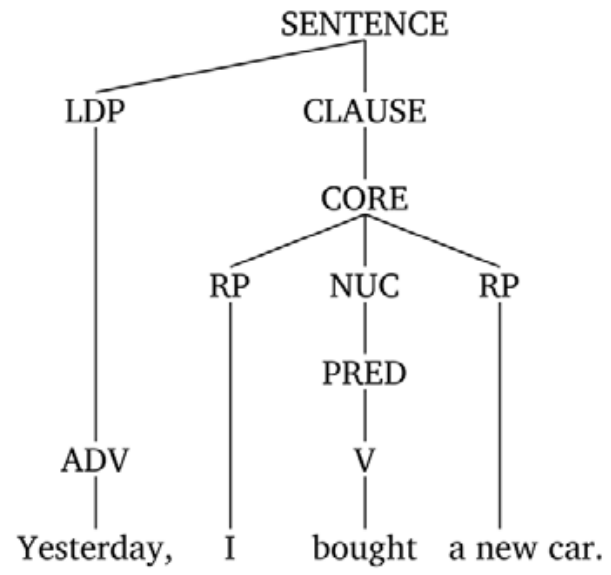

Figure 5: English sentence with an LDP

(adapted from Van Valin 2005: 6). 
Van Valin (2005: 8) points out that the pragmatically motivated units (the detached positions and extracore slots) are not universal, whereas the other syntactic units are universal. This means that not all languages will have an extracore slot, whereas others will have both and still others will only have one. Van Valin (2005: 17) stresses that the extracore slots cannot contain more than one RP or PP at a time and that there can never be more than one such slot in the clause. It is possible in some languages to have a semantic argument of the predicate in a detached position. If this is the case, a resumptive pronoun will be present in the core (Van Valin 2005: 6). Van Valin offers an example from English, but the situation in Dutch is similar: Ik ken hem, je broer ('I know him, your brother') or Ik zie het, dat onweer ('I see it, that thunderstorm'). Consider:

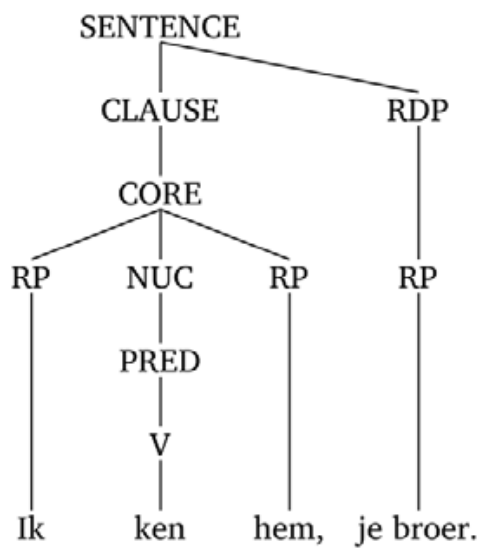

Figure 6: Dutch sentence with an RDP and a resumptive pronoun in the core.

RRG assumes that the syntactic structures are stored as templates in the syntactic inventory rather than being derived by any kind of phrase structure rule (Van Valin 2005: 13). As different languages show different configurations in the constituent projection, the templates in the syntactic inventory are not universal but subject to considerable crosslinguistic variation. In short, the content of the syntactic inventory is language specific. Judging from the Dutch examples in figures 4 and 6, 
we can theorize that Dutch has (at least!) a right detached positiontemplate, a precore slot-template and two different core templates. Within the process of linking semantics to syntax, the correct templates are selected and merged to form the complete structure that is depicted in the constituent projection. This non-exhaustive Dutch inventory is given in figure 7 .

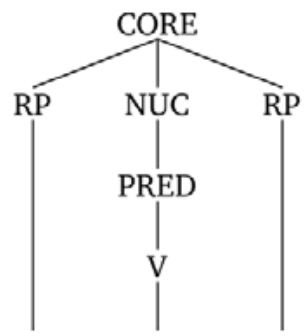

Core-1 template

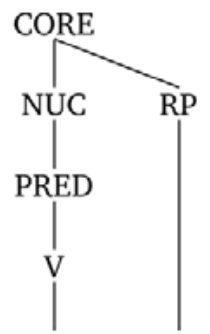

Core-2 template

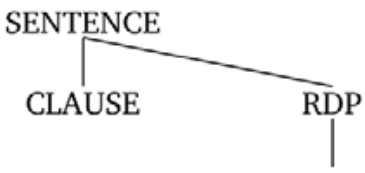

RDP template

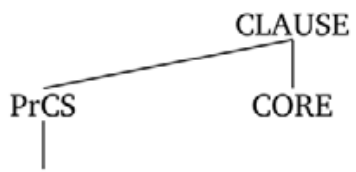

PrCS template

Figure 7: A non-exhaustive list of Dutch syntactic templates in the syntactic inventory.

It has been previously explained that the periphery contains the nonarguments, the adjuncts. Van Valin (2005: 19) distinguishes between phrasal and non-phrasal adjuncts. PPs are an example of the former, adverbs an example of the latter. An element of the periphery, depending on its precise content, can modify any layer of the LSC. Van Valin (2005: 19) posits that temporal or locational PPs (such as in figure 3) modify the events encoded by the elements of the core. Consequently, 
the periphery that contains them modifies the core level. Adverbs may modify all three layers of the LSC, depending on their nature. For example, a manner adverb like carefully modifies the core, but an aspectual adverb like completely modifies the nucleus.

Generally speaking, the structure of phrases is similar to that of clauses (Van Valin 2008, Van Valin 2005: 24): both have a layered structure, both have a set of operators modifying this structure and a (potential) periphery for each level. The phrase level is equivalent to the clause and sentence levels in the LSC. Parallel to the LSC, there is a nucleus and a core $^{3}$. The nucleus in an RP is usually filled by a noun but is not restricted just to nouns. Similar to the nucleus in the LSC, other categories such as verbs and adjectives can function as filler (Van Valin 2008, Van Valin 2005: 28). 'Core arguments' can occur in certain complex RPs. Adjectives are treated as modifiers in the nuclear ${ }_{R}$ periphery. Similarly to adverbs in the clause, they are constrained by iconicity: Adjectives must occur closer to the nucleus than other modifiers and operators (Van Valin 2005: 26).

Phrases can also have a unit which functions like an extracore slot and a detached position (Van Valin 2005: 26). Similar to both units in the LSC, this 'RP-slot' can be phrase initial or phrase final, depending on the language. They are therefore termed the RP-initial position (RPIP) and $R P$-final position (RPFP) respectively. All of these units are also stored as templates in the syntactic inventory (Van Valin 2005: 24). An example for the structure of an RP is given below. The Dutch example reads 'big bridges' and is adapted from Van Valin (2005: 25).

3 In the projections, a subscript $\mathrm{R}$ identifies a given unit as belonging to a reference phrase. Thus CORER is the nominal core. 


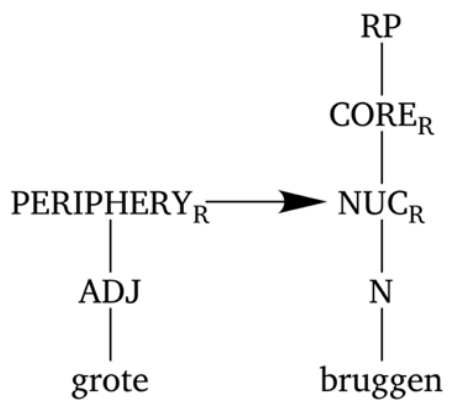

Figure 8: The layered structure of a Reference Phrase.

The account presented above applies to phrase structure in general. There is however an important addition to be made concerning the nature of prepositional phrases. Van Valin (2005: 21-23) points out that from the RRG-perspective, $\mathrm{PPs}^{4}$ can be predicative or non-predicative. Non-predicative PPs are characterized by a flat structure. They are - as the name suggests - licensed by the predicate and do not predicate anything themselves. They are, in other words, core arguments and the preposition is considered to be a type of case marker, an insight also shared by, for example, Fillmore (1968, 1977a). In the sentence fohn gave a book to Mary, the PP to Mary is a non-predicative PP functioning as a core argument ${ }^{5}$.

A predicative $\mathrm{PP}$ is a $\mathrm{PP}$ where the adposition itself licenses an argument, contributing semantic information. Such PPs are usually found in the core periphery. A locational PP, such as the one in figure 3 , is a good example. The location coded by the phrase is licensed by the adposition. Figure 9 shows both types of PPs (adapted from Van Valin 2005: 23).

$4 \quad$ It would probably be more precise to use the term AP (adpositional phrase) as this distinction also applies to postpositional phrases in language where they occur.

5 A core argument marked by a preposition is termed Oblique Core Argument in RRG. Core arguments not marked thus are Direct Core Arguments (Van Valin 2005: 7). 

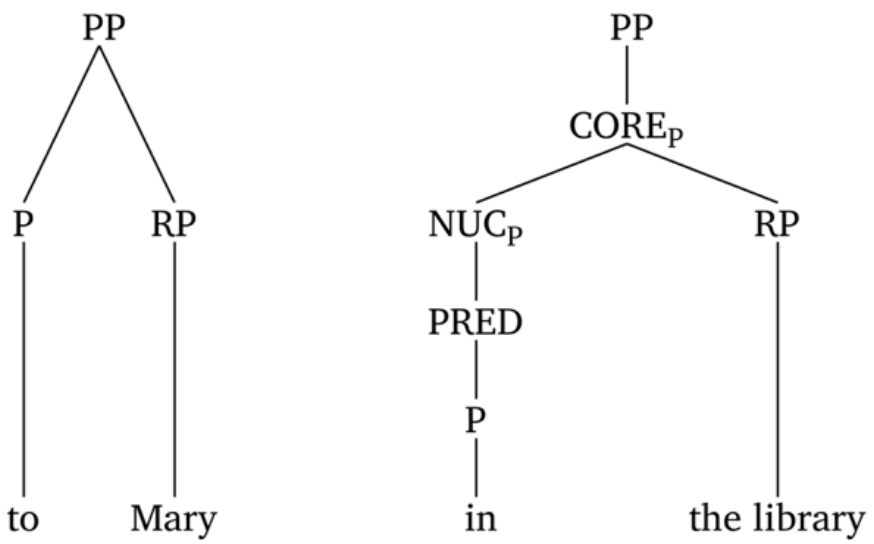

Figure 9: A non-predicative and a predicative PP in English.

\subsubsection{Operator Projection}

RRG treats grammatical categories such as tense and aspect as operators modifying different layers of the clause (Van Valin 2005: 8). Some operators can only modify one layer (e.g. aspect), whereas negation is the only operator that can occur on all three levels ${ }^{6}$ (Van Valin 2005: 9). Van Valin crucially points out that operators are largely language-specific; only negation and illocutionary force are universal. Even though operators modify the different layers of the LSC they are separate from them (Van Valin 2005: 11). Therefore, they warrant a separate projection; the operator projection. A list of operators is given in the table below (Van Valin 2005: 9).

$6 \quad$ It is to be remarked, however, that there are still important differences between negation on the different levels. This is a complex matter, which I will not go into here. 


\begin{tabular}{|l|l|l|}
\hline \multicolumn{3}{|c|}{ Operators in the LSC } \\
\hline Nuclear & Core & Clausal \\
\hline Aspect & Directionals & Status $^{7}$ \\
\hline Negation & Event quantification $^{10}$ & Tense \\
\hline Directionals & Modality $^{10}$ & Evidentials \\
\cline { 2 - 3 } & $\begin{array}{l}\text { Internal (narrow } \\
\text { scope) negation }\end{array}$ & Illocutionary Force \\
\hline
\end{tabular}

Table 2: Summary of operators in the LSC.

The operator projection is treated as the mirror image of the constituent projection. The morphological expression of an operator is connected with a dashed line to the respective layer it modifies. It is crucial to point out that an iconic Universal Scope Constraint applies in RRG in various ways (Van Valin 2005: 11, 12 and 21). This principle dictates that the morphemes expressing nuclear operators occur closer to the verb (stem) than morphemes expressing core operators. In turn, morphemes expressing clausal operators must occur outside of those expressing core operators. According to Van Valin (2005: 11), no counter-examples to this ordering principle have been found to date. The sentence from figure 3 is repeated in figure 10, this time with the matching operator projection.

Adverbs interact quite intensely with operators and they are iconically constrained by the operator projection and the scope of different operators. That is to say, adverbs related to inner operators must be closer to the predicate than adverbs related to (more) outer operators (Van Valin 2005: 20). 'Outer' operators are to be understood as operators operating on a higher level of the LSC. Ergo, nuclear adverbs must occur closer to the predicate than core adverbs. In turn, core adverbs must occur closer to the predicate than clausal adverbs (Van Valin 2005: 21).

7 Only those expressing the orientation or motion of one participant with reference to another participant or to the speaker.

8 Epistemic modals, external negation.

9 Only those modifying orientation of action or event without reference to participants.

10 Root modals, e.g. ability, permission, obligation. 


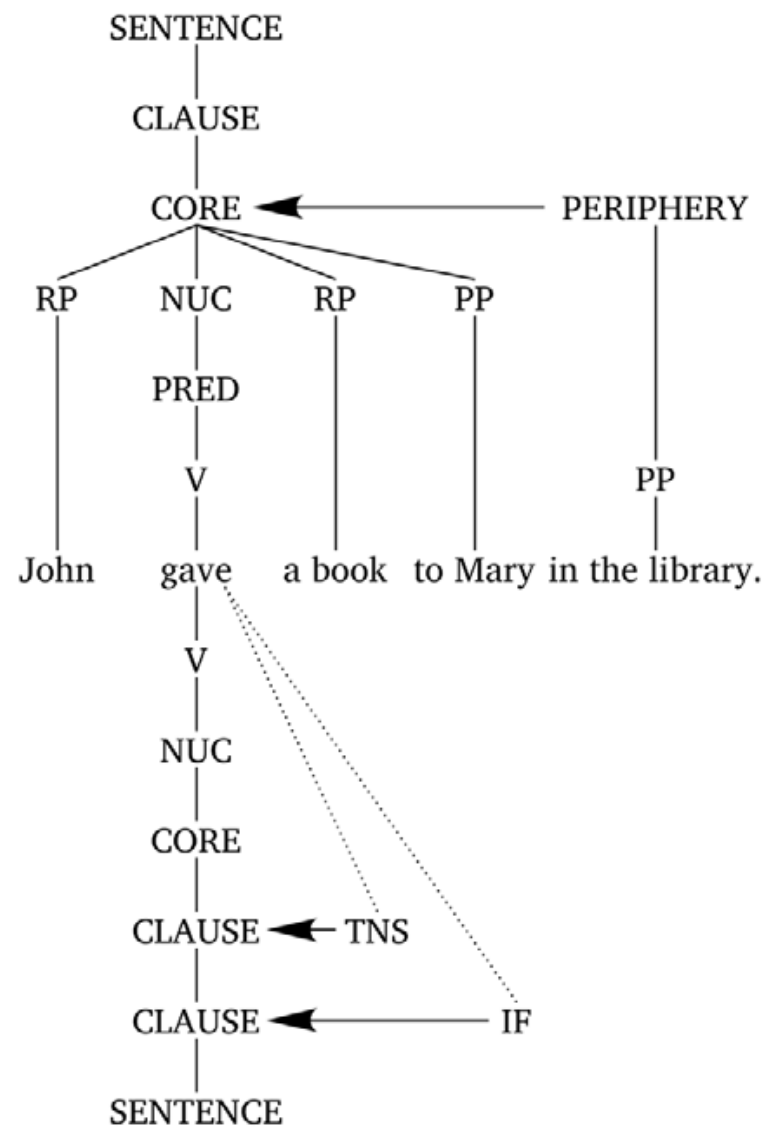

Figure 10: Constituent and operator projections of an English sentence.

Similar to the LSC, phrases have their proper set of operators and an operator projection. These operators have scope over different levels, as is the case with the LSC. For example, definiteness is an RP-level operator whereas quantification is a core level operator. A list of RP-operators is provided below (Van Valin 2005: 24). 


\begin{tabular}{|l|l|l|}
\hline \multicolumn{2}{|c|}{ Operators in the layered structure of the RP } \\
\hline Nuclear $_{\mathbf{R}}$ & Core $_{\mathbf{R}}$ & RP \\
\hline Nominal aspect $^{11}$ & Number & Definiteness \\
\cline { 2 - 3 } & $\begin{array}{l}\text { Quantification (quanti- } \\
\text { fiers) }\end{array}$ & Deixis \\
\cline { 2 - 2 } & Negation & \\
\hline
\end{tabular}

Table 3: Operators in the layered structure of the RP.

The example of the RP in the previous section only had a constituent projection. Expanding the phrase from figure 8 to de drie grote bruggen ('the three big bridges') involves including operators. The expanded phrase is given below, this time with the operator projection included.

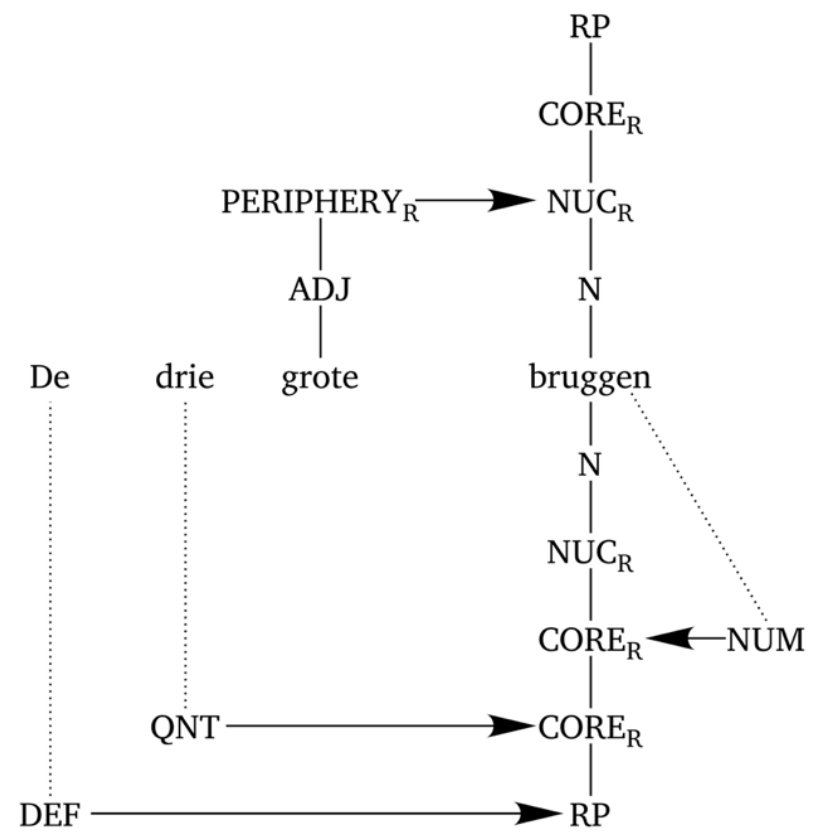

Figure 11: Constituent and operator projections of a Dutch RP.

11 Count-mass distinction, classifiers in classifier languages. 
It is crucial to point out that the operator projection is just that, a projection. Operators can be included in the logical structure of a sentence (or can be omitted for the sake of clarity) to represent the scope of each within this structure.

\subsection{The Semantic Architecture of Role and Reference Grammar}

\subsubsection{Aktionsarten}

RRG is a semantically driven syntactic theory. The semantic representation of sentences is directly based on the semantic representation of the predicating element (usually the verb). It is crucial to describe and capture the semantic relationships that hold between a predicate and its arguments. As the most typical predicate is a verb, a systematic theory of verb classes is at the heart of Role and Reference Grammar. RRG assumes that verbs can be classified according to their aktionsarten (Vendler 1957, 1967). It recognizes the Vendlerian aktionsart classes but also includes non-Vendlerian classes. Each class can be defined over a set of features, summarized in a feature matrix. Van Valin (2005: 32) points out that there is great cross-linguistic validity to the proposed verb classes. Hence, it is not unreasonable to assume that these distinctions are universal to human language.

Four features characterize the aktionsart classes: [ \pm static], [ \pm dynamic], [ \pm telic] and [ \pm punctual]. I provide a short description of each of them, followed by an overview of tests that help determine the precise aktionsart class.

Van Valin points out that [+static] verbs code a 'non-happening', whereas [-static] refers to a 'happening' (Van Valin 2005: 33). A fairly rudimentary way to test this is to ask the question 'what is happening?'. If the sentence that is to be tested could be a possible answer, then the verb is [-static]. For example, fohn is running could be an answer to that question but fohn knows Mary is not. Hence, run is [-static] and know is [+static]. 
The feature [ \pm dynamic] is related to whether or not the situation coded by the verb involves action. [+dynamic] verbs can be modified by socalled dynamic adverbs such as violently amongst others. This also constitutes the test for this feature (see below).

The feature [ \pm telic] refers to whether or not the situation coded by the verb has an endpoint. [+telic] verbs do, [-telic] verbs do not have an inherent endpoint. In a sentence like fohn knows Mary the verb (a state) does not have an inherent endpoint, making it [-telic]. This can be contrasted with the ice melted where the point in time where the ice has completely turned to water is the inherent endpoint.

The feature [ \pm punctual] refers to whether or not the situation coded by the verb has internal duration. In a sentence like the window shattered, the event coded by the verb is a punctual change-of-state. The change-of-state occurs instantaneously. As such, it is considered [+punctual]. The feature matrix for all classes is given in table 4 (Van Valin 2005: 33).

\begin{tabular}{|c|c|c|c|c|}
\hline Class & \multicolumn{4}{|c|}{ Features } \\
\hline State & [+static] & [-dynamic] & [-telic] & [-punctual] \\
\hline Activity & [-static] & [+dynamic] & [-telic] & [-punctual] \\
\hline Achievement & [-static] & [-dynamic] & [+telic] & [+punctual] \\
\hline Semelfactive & [-static] & {$[ \pm$ dynamic $]$} & [-telic] & [+punctual] \\
\hline Accomplishment & [-static] & [-dynamic] & [+telic] & [-punctual] \\
\hline $\begin{array}{l}\text { Active } \\
\text { accomplishment }\end{array}$ & [-static] & [+dynamic] & [+telic] & [-punctual] \\
\hline
\end{tabular}

Table 4: Feature matrix for the base aktionsart classes as recognized by RRG.

Two of these classes, however, warrant a closer look: semelfactives and active accomplishments. Semelfactives are pure, punctual events without a change of state. Examples include sentences like the light flashed (Van Valin 2005: 32), where the state of the light after the event is identical to the state of the light before the flashing took place. In other words, there is no result state. There is one further important point to make with respect to semelfactives. In the feature matrix they are listed as either 
[+dynamic] or [-dynamic]. This simply reflects the fact that some semelfactives are indeed dynamic in nature, a fact which is represented by a do' $^{\prime}$ in the logical structure (see below). Consider (adapted from Van Valin 2005: 31ff.):

(2) a. The light flashed ( ${ }^{*}$ violently).

b. John coughed (violently).

The acceptability of the adverb in (2b) and the unacceptability of that adverb in (2a) show that semelfactives do come in two flavors. This has to be borne in mind when applying the aktionsart tests.

The most important non-Vendlerian aktionsart is the active accomplishment. Active accomplishments can be considered as telically used activity predicates (Van Valin 2005: 32). They are derived from activity predicates, a fact that becomes very clear in the logical structure of both classes: the LS of an active accomplishment is a subset of the LS of an activity predicate (see below for further details). Consider the following examples (adapted from Van Valin 2005: 33):
a. I ran.
$=$ activity
b. I ran to the park.
$=$ active accomplishment
c. Dana ate fish.
= activity
d. Dana ate the fish.
$=$ active accomplishment

All of these aktionsart classes have causative counterparts. These classes will be discussed in more detail in the following sections.

Drawing from the work of different linguists, RRG provides a set of tests with which the precise patterning of a given verb in a given language can be determined. It is, however, crucial to realize that these tests come with numerous caveats. First, the tests have to be adapted to fit the language under investigation (Van Valin 2005: 35). For example, tests 4 and 5 use the format [Prep + unit of time]. In Van Valin (2005) and in this chapter, the tests appear in an English-specific format (in an hourvs. for an hour). In the case of the for/in-alternation, it has to be determined how the language in question expresses for and in in their temporal senses (Van Valin 205: 37). Second, these tests have their limitations with respect to individual verbs. For example, the verb bleed is an activity but 
is not compatible with dynamic adverbs and thus fails test 2 (Jens Fleischhauer, p.c.). Despite these limitations, the tests are a powerful tool to determine the aktionart class of a given predicate. The account presented below is the one presented in Van Valin (2005) and represents the standard RRG-account.

Test 1 involves the use of the progressive and identifies a verb as an actvity, an accomplishment or an active accomplishment if it is compatible with the progressive. With the other classes, the progressive is less (or not at all) compatible. Consider for example the questionable grammaticality of sentences like *The glass was shattering or ${ }^{*} I$ was seeing the painting. Most states disallow the progressive altogether, whereas achievements seem to allow it with plural subjects only. Semelfactives can occur with the progressive, but only in an iterative reading (Van Valin 2005: 35-36). In both cases, the verb patterns like an activity verb and no longer like an achievement or a semelfactive, respectively (Van Valin 2005: 36). Causative states are particularly interesting in this regard. Causative states allow the progressive more easily when the state of affairs described by the sentence is more actional in nature. Consider (Van Valin 2005: 39) the sentence your attitude upsets/?is upsetting me as compared to your boorish behavior upsets/is upsetting me. There are two important caveats with this test: 1) it is only useful if the language in question has progressive aspect and 2) it does not isolate a singular property. Rather, it sets three classes apart from the others (Van Valin 2005: 35). I have therefore listed the property tested by test 1 as 'multiple ${ }^{*}$ in table 6.

Test 2 involves the use of dynamic adverbs and isolates [ \pm dynamic]. The compatibility of the verb under investigation with an adverb encoding a dynamic action reveals a positive value for dynamicity. An important restriction for this test is that no dynamic adverb be used that requires a controlling subject (Van Valin 2005: 36). Doing so would mean mixing the properties [ \pm dynamic] and [ \pm controlling] which could yield wrong or distorted results. Incompatibility might then be due to the agentive reading of the adverb conflicting with semantic properties of the verb. Consider (Van Valin 2005: 36) the examples in (4). 

a. The dog shivered.
Activity $([+$ dynamic $])$
b. The dog shivered violently.
Activity $([+$ dynamic $])$
c. ${ }^{*}$ The dog shivered deliberately.
Activity $([+$ dynamic $])$

With test 2, causative states again present an interesting, additional complication: The more actional the state of affairs described by the sentence is, the more acceptable dynamic adverbs will be, e.g. (Van Valin 2005: 40) The clown actively amused the children.

Test 3 isolates [ \pm punctual] and involves using pace adverbs (e.g.: quickly, rapidly, slowly etc.). In other words, test 3 tests whether or not a verb has temporal duration. If the pace adverb and the verb are compatible, the verb has temporal duration and thus is [-punctual]. For example: The ice melted slowly (melt = accomplishment, [-punctual]) as opposed to ${ }^{*}$ The window shattered slowly (shatter $=$ achievement, [+punctual]). This test is not linked through any kind of redundancy with test 2 . These pace adverbs are compatible with [-punctual] irrespective of the dynamicity of the verb. For example (after Van Valin 2005: 36): The ice melted slowly as opposed to ${ }^{*}$ The ice melted violently. The main caveat with test 3 is that adverbs denoting very short units of time distort the test results. Using such adverbs could lead the user to wrongly rate [+punctual] predicates, such as achievements and semelfactives, as [-punctual]. Consider for example (Van Valin 2005: 36-37) the sentence the bomb exploded instantly/* gradually (achievement, [+punctual]). Semelfactives, again, seem to allow for an iterative reading ${ }^{12}$, making them pattern like activities (see above). It is thus important to use adverbs denoting an adequately long temporal interval.

Test 4 involves adding (in English) a for-PP with a temporal meaning. As such, this test focusses on whether a verb has temporal duration or not. Consider the sentence (Van Valin 2005: 37) he read the book for an hour. The PP specifies that the event denoted by the verb went on for a certain amount of time. No reference to any endpoint is given. All classes except achievements and semelfactives are compatible with for-PPs and thus have duration in time. Semelfactives are only compatible with

12 To counteract any iterative reading, once (or a similar adverb) can be added (Van Valin 2005: 36-37). 
for-PPs denoting very short time spans. An important caveat with this test is that states denoting inherent properties do not take for-PPs (Van Valin 2005: 37) as in for example ?fohn was intelligent for an hour. One last remark needs to be made. Accomplishments and active accomplishments can co-occur with for-PPs. Van Valin (2005: 37-38) points out that this follows from their [-punctual] nature (as determined by test 3). Van Valin (2005: 37-38) considers the occurrence of for-PPs with these classes irrelevant and they are therefore marked as such in table 5.

Test 5 is often used in conjunction with test 4 and uses an in-PP with a temporal meaning. This test focuses on terminal points (Van Valin 2005: 37). In the sentence he read the book in an hour, the act of reading is complete. The reading took one hour and the book has been finished. A caveat with test 5 is that even though achievements have an endpoint (i.e. [+telic]) they are incompatible with most in-PPs due to their [+punctual] nature. Only PPs denoting very short time segments are possible (e.g. in a fraction of a second). Practically speaking, accomplishments, active accomplishments and their causative counterparts take inPPs. Tests 4 and 5 are often collectively known as the for/in-alternation and are used to distinguish the [+telic] classes from the [-telic] classes. Van Valin points out that both tests should be used with 'temporal expressions of substantial duration' (Van Valin 2005: 37).

Both semelfactives and achievements are [+punctual] and test 6 is used to distinguish them. The verb is used as a stative modifier. Consider (after Van Valin 2005: 38):

(5) a. The window shattered $\rightarrow$ The shattered window.

b. The light flashed. $\rightarrow{ }^{*}$ The flashed light.

As semelfactives are pure events without a result state, they cannot be used as a stative modifier.

Test 7 makes use of a paraphrase to ascertain whether the verb is causative or not. It is however crucial that the number of arguments remain constant: All the arguments of the original sentence have to feature in the paraphrase. Consider the examples (Van Valin 2005: 38) in (6). 
(6) a. The cat popped the balloon.

The cat caused the balloon to pop.

b. The hot water melted the ice.

The hot water caused the ice to melt.

c. Leslie runs.

${ }^{*}$ Leslie causes to run. $/{ }^{*}$ Leslie causes herself to run.

It is important to stress that this test cannot be applied to singleargument verbs as using a cause-paraphrase with only one argument is not possible (6c). Causativity always includes (at least) two participants. Values with caveats are marked with an asterisk in the table. Table 5 is a summary of the aktionsart tests and their result when applied to the individual classes including the causative versions of each (Van Valin 2005: 39). Table 6 is a summary of the aktionsart tests, the properties that they test and possible caveats. Note that the question-answer pairing has been included as test 1'. It is not featured in Van Valin (2005) as a test in its own right, but due to its usefulness it should be included here. The causative classes are derived from the non-causatives ones, a fact which is represented in the table. The tests were applied to all example sentences in this book. 


\begin{tabular}{|c|c|c|c|c|c|c|c|}
\hline Class & T1 & $\mathrm{T} 2$ & T3 & T4 & T5 & T6 & T7 \\
\hline State & $\mathrm{No}^{*}$ & No & No & Yes* $^{*}$ & No & Yes & No \\
\hline Achievement & $\mathrm{No}^{*}$ & No & $\mathrm{No}^{*}$ & $\mathrm{No}^{*}$ & $\mathrm{No}^{*}$ & Yes & No \\
\hline Semelfactive & $\mathrm{No}^{*}$ & $\mathrm{No}^{*}$ & $\mathrm{No}^{*}$ & Yes $^{*}$ & $\mathrm{No}^{*}$ & No & No \\
\hline Accomplishment & Yes & No & Yes & Irrelevant $^{*}$ & Yes & Yes & No \\
\hline Activity & Yes & Yes & Yes & Yes & No & No & No \\
\hline $\begin{array}{l}\text { Active } \\
\text { accomplishment }\end{array}$ & Yes & Yes & Yes & Irrelevant* & Yes & Yes & No \\
\hline Causative state & Yes* $^{*}$ & Yes $^{*}$ & No & Yes & No & Yes & Yes \\
\hline $\begin{array}{l}\text { Causautive } \\
\text { achievement }\end{array}$ & No & Yes $^{*}$ & $\mathrm{No}^{*}$ & No & $\mathrm{No}^{*}$ & Yes & Yes \\
\hline $\begin{array}{l}\text { Causative } \\
\text { semelfactive }\end{array}$ & $\mathrm{No}^{*}$ & Yes $^{*}$ & $\mathrm{No}^{*}$ & $\mathrm{No}^{*}$ & $\mathrm{No}^{*}$ & No & Yes \\
\hline $\begin{array}{l}\text { Causative } \\
\text { accomplishment }\end{array}$ & Yes & Yes $^{*}$ & Yes & Irrelevant* & Yes & Yes & Yes \\
\hline $\begin{array}{l}\text { Causative } \\
\text { activity }\end{array}$ & Yes & Yes & Yes & Yes & No & Yes & Yes \\
\hline $\begin{array}{l}\text { Caus. active } \\
\text { accomplishment }\end{array}$ & Yes & Yes & Yes & Irrelevant $^{*}$ & Yes & Yes & Yes \\
\hline
\end{tabular}

Table 5: Aktionsart tests and the values for the respective aktionsart classes. 


\begin{tabular}{|c|c|c|c|}
\hline Test & Format & Property tested & Caveat \\
\hline 1 & Progressive & Multiple* $^{*}$ & $\begin{array}{l}\text { Only in } \\
\text { languages with } \\
\text { progressive } \\
\text { aspect }\end{array}$ \\
\hline 2 & Dynamic adverb & {$[ \pm$ dynamic $]$} & $\begin{array}{l}\text { Avoid adverbs } \\
\text { with controlling } \\
\text { subject }\end{array}$ \\
\hline 3 & Pace adverb & {$[ \pm$ punctual $]$} & $\begin{array}{l}\text { Avoid time units } \\
\text { that are very } \\
\text { short }\end{array}$ \\
\hline 4 & For-PP & Temporal duration & $\begin{array}{l}\text { (1) Semelfactives } \\
\text { only with PPs } \\
\text { denoting very } \\
\text { short intervals } \\
\text { (2) Not with state } \\
\text { predicates } \\
\text { denoting inher- } \\
\text { ent properties }\end{array}$ \\
\hline 5 & In-PP & Terminal point & $\begin{array}{l}\text { Achievements } \\
\text { only possible } \\
\text { with PPs denot- } \\
\text { ing very short } \\
\text { intervals }\end{array}$ \\
\hline 6 & Stative modifier & $\begin{array}{l}\text { Result state with } \\
{[+ \text { punctual }] \text { verb }}\end{array}$ & \\
\hline 7 & $\begin{array}{l}\text { Causative para- } \\
\text { phrase }\end{array}$ & Causativity & $\begin{array}{l}\text { Maintain number } \\
\text { of arguments! }\end{array}$ \\
\hline $1^{\prime}$ & Question-answer & [ \pm static $]$ & \\
\hline
\end{tabular}

Table 6: Summary of aktionsart tests with tested properties and caveats. 


\subsubsection{Logical structures}

Each aktionsart class is represented by a certain logical structure. In RRG, the system of lexical decomposition proposed by Dowty (1979) in a modified form is used as the basis for the logical structures. RRG assumes that the LSs of the aktionsart classes are all derived from either an activity or a state predicate. States are represented as bare predicates whereas activities are characterized by the predicate do' in their logical structure. In other words, activities and states are basic and all others are derived from them (Van Valin 2005: 42). Achievements are characterized by the presence of the operator INGR (ingressive), accomplishments by the presence of BECOME. Semelfactives are characterized by the presence of the SEML-operator and causatives are characterized by the CAUSE-operator. It is to be borne in mind that causative predicates have a more complex logical structure following the pattern $\alpha$ CAUSE $\beta$, where $\alpha$ and $\beta$ are logical structures of any type (Van Valin 2005: 45).

In the LS, each of the aktionsart classes is represented as an operator or combination of operators. Bold face indicates a predicate and the variables $\mathrm{x}, \mathrm{y}$ and $\mathrm{z}$ represent the argument slots. A list of sentences with their corresponding logical structures (adapted from Van Valin 2005: $42 \mathrm{ff}$.) is given in (7).
a. John knows Pat.
State
know' (John, Pat)
b. Carl ate pizza.
Activity
do' (Carl, [eat' (Carl, pizza)])
c. The window shattered.
INGR shattered' (window)
Achievement
d. The ice melted.
BECOME melted' (ice)
e. Dana glimpsed the picture. Semelfactive (stative) SEML glimpse' (Dana, picture)
f. Mary coughed.
SEML do' (Mary, [cough' (Mary)])
g. Chris ran to the park. Active accomplishment do' (Chris, [run' (Chris)]) \& INGR be-at' (park, Chris)


h. The dog scared the boy. Causative state [do' (dog, Ø)] CAUSE [feel' (boy, [afraid'])]

i. The girl walked the dog. Causative activity [do' (girl, Ø)] CAUSE [do' (dog, [walk' (dog)])]

j. The cat popped the balloon. Causative achievement [do' (cat, Ø)] CAUSE [INGR popped' (balloon)]

k. The hot water melted the ice. Causative accomplishment

[do' (hot water, Ø)] CAUSE [BECOME melted' (ice)

1. The soldier flashed the light. Causative semelfactive

[do' (soldier, Ø)] CAUSE [SEML do' (light, [flash' (light)])]

m. The Praetor marched the soldiers to the fort.

Causative active accomplishment [do' (Praetor, Ø)] CAUSE [do' (soldiers, [march' (soldier)]) \& INGR be-at' (fort, soldiers)]

A small note on causation has to be made at this point. Van Valin (2005: 42) distinguishes between three kinds of causation: direct, indirect and permissive causation. The former two are represented by CAUSE in the logical structure, the latter is represented by LET. However, in the logical structures the (potential) distinctions are generalized over for practical reasons (Van Valin, p.c.). This means that the three types of causation are amalgamated - as far as the LS is concerned - into CAUSE. Table 7 is a summary of possible LS-configurations. 


\begin{tabular}{|c|c|}
\hline Aktionsart Class & Logical Structure \\
\hline STATE & predicate $^{\prime}(\mathrm{x})$ or $(\mathrm{x}, \mathrm{y})$ \\
\hline ACTIVITY & do $^{\prime}(\mathrm{x}$, [predicate $(\mathrm{x})$ or $\left.(\mathrm{x}, \mathrm{y})]\right)$ \\
\hline ACHIEVEMENT & $\begin{array}{l}\text { INGR predicate' }(\mathrm{x}) \text { or }(\mathrm{x}, \mathrm{y}) \text { or } \\
\text { INGR do' }\left(\mathrm{x},\left[\text { predicate }^{\prime}(\mathrm{x}) \text { or }(\mathrm{x}, \mathrm{y})\right]\right)\end{array}$ \\
\hline SEMELFACTIVE & $\begin{array}{l}\text { SEML predicate' }(\mathrm{x}) \text { or }(\mathrm{x}, \mathrm{y}) \text { or } \\
\text { SEML do' }(\mathrm{x}, \text { [predicate' }(\mathrm{x}) \text { or }(\mathrm{x}, \mathrm{y})])\end{array}$ \\
\hline ACCOMPLISHMENT & $\begin{array}{l}\text { BECOME predicate' }(\mathrm{x}),(\mathrm{x}, \mathrm{y}) \text { or } \\
\text { BECOME do }^{\prime}\left(\mathrm{x},\left[\text { predicate }^{\prime}(\mathrm{x}) \text { or }(\mathrm{x}, \mathrm{y})\right]\right)\end{array}$ \\
\hline $\begin{array}{l}\text { ACTIVE } \\
\text { ACCOMPLISHMENT }\end{array}$ & $\begin{array}{l}\text { do }^{\prime}\left(\mathrm{x},\left[\text { predicate1 }^{\prime}(\mathrm{x},(\mathrm{y}))\right]\right) \text { \& INGR pred- } \\
\text { icate2 }^{\prime}(\mathrm{z}, \mathrm{x}) \text { or }(\mathrm{y})\end{array}$ \\
\hline CAUSATIVE & $\begin{array}{l}\alpha \text { CAUSE } \beta \text {, where } \alpha, \beta \text { are logical structure } \\
\text { of any type }\end{array}$ \\
\hline
\end{tabular}

Table 7: Lexical representations for aktionsart classes (Van Valin 2005: 45).

\subsection{Linking semantics to syntax}

In the previous sections, I have introduced the basics of the syntactic representation and the semantics of the theory. In the following sections, the mechanisms relating semantics to syntax will be discussed.

\subsubsection{The Actor-Undergoer Hierarchy and the Macroroles}

In the linking of the semantic base into the syntax, RRG employs two crucial tools: the macroroles (actor and undergoer) and the actorundergoer hierarchy (AUH). Macroroles (Van Valin 2005: 60, Van Valin \& LaPolla 1997, Van Valin 1977, 1999 and 2004, Foley \& Van Valin 1984) are generalized semantic roles or GSRs.

GSRs have been proposed by various scholars in recent decades, in various incarnations (see Levin \& Rappaport Hovav 2005: 51ff.). Dowty, for example, posits semantic proto-roles as cluster concepts rather than as discrete semantic roles. Van Valin (1999: 373) points out that GSRs have important functions in monostratal theories of syntax as they are 
employed to capture important generalizations that are handled in terms of deep subjects and objects (and similar devices) in the various versions of transformational grammar. The main motivation behind GSRs is that there is a fundamental opposition between the two cardinal arguments of a transitive predication (Van Valin 1999: 373, 2005: 60-61). Van Valin points out that many syntactic phenomena are tied to these two cardinal arguments. RRG's macroroles are similar to Dowty's proto-roles in that both are derived concepts with no invariant semantic entailments (Levin \& Rappaport Hovav 2005: 68), but they differ with respect to their importance for linking mechanisms (Ibid.) In RRG, they occupy a prominent position in many aspects of the system. It is crucial to stress that GSRs are not thematic relations. Rather, Van Valin distinguishes (1999: 373) between three levels of semantic relationships: verb-specific semantic roles, thematic relations as generalizations across verb-specific roles and, finally, GSRs as generalizations across thematic relations. The first type does not really play any role in RRG, the second can play a role in interpretation and differences therein. For linking, the GSRs are by far the most important ones. GSRs are partly motivated by similar considerations that inspired the concept of thematic relations (e.g. active vs. passive sentences). GSRs are, however, an attempt to address the inherent shortcomings of standard thematic relations (Dowty 1991). Due to their generalized nature, they are much more robust and adequate to capture the behavior of a grammatical system. Most approaches using GSRs have two such roles, although some linguists posit three roles (e.g. Primus 1999). Van Valin (1999) provides arguments against three macroroles, defending the dual nature of RRG's GSR-conception. First, some languages disprefer or even completely prohibit three arguments in a single core (Van Valin 2004: 74ff). Therefore, a hypothetical third macrorole can never be universal. As such, it would not be adequate to use as a cornerstone of syntactic theory. Second, morphosyntactic coding of actor and undergoer is fairly consistent cross-linguistically, contrary to the coding of the third argument in a ditransitive predication (Ibid.), which is typologically not consistent at all.

RRG's macroroles are semantic notions that play a crucial role in the syntax (Van Valin 2004: 64). As was explained above, actor and 
undergoer are distinct from both thematic relations and syntactic relations such as subject and direct object. RRG does not use these latter two concepts because they are deemed to be non-universal (Van Valin 2005: 89ff.). Rather, actor and undergoer are the pivotal linking concepts in RRG. Put simply, the actor is the most agent-like argument and the undergoer is (usually) the most patient-like argument. Altough the notions have no place in RRG, actor and undergoer can be (more or less) equated to 'logical subject' and 'logical object'. The third argument of ditransitive verbs is treated as a non-macrorole argument (NMR). This means that the argument in question simply does not receive a macrorole. Singleargument verbs have either the actor or the undergoer macrorole, correlating with the respective presence or absence of do' in the logical structure (Van Valin 2005: 63). Throughout the linking process, reference is made to the macroroles and, to a lesser extent, the NMR (for example in the domain of case assignment - Van Valin 2009a and Van Valin 2005: 108-110).

Because the base semantics in RRG are dealt with in terms of logical structures, the assignment of macroroles to arguments of the predicate can be described in terms of the argument positions relative to each other. The more 'agent'-like arguments will be to the left (in the LS) of the more 'patient'-like arguments. It is therefore possible to capture the relation between macroroles and the arguments in the LS in terms of a hierarchy, the Actor-Undergoer Hierarchy (Van Valin 2005: 61 \& 126):

\begin{tabular}{lllll} 
ACTOR & & & UNDERGOER \\
\hline $\begin{array}{l}\text { Arg. of } \\
\text { DO }\end{array}$ & $\begin{array}{c}1^{\text {st }} \text { arg. of } \\
\text { do' }^{\prime}(\mathrm{x}, \ldots\end{array}$ & $\begin{array}{l}1^{\text {st }} \text { arg. of } \\
\text { pred }^{\prime}(\mathrm{x}, \mathrm{y})\end{array}$ & $\begin{array}{l}2^{\text {nd }} \text { arg. of } \\
\text { pred' }(\mathrm{x}, \mathrm{y})\end{array}$ & $\begin{array}{l}\text { Arg. of } \\
\text { pred' }(\mathrm{x})\end{array}$ \\
{$[\longrightarrow$} & = increasing markedness of realization of argument as macrorole $]$
\end{tabular}

Figure 12: The Actor-Undergoer Hierarchy (AUH).

The argument in the LS that ranks highest on the AUH is selected as actor, the argument that ranks lowest is selected as undergoer. If there is a third argument, it is neither the highest nor the lowest and therefore becomes the non-macrorole argument (NMR). Actor assignment is not 
variable. Undergoer assignment is variable, although there is a default. Variable undergoer selection is possible in certain languages, such as English and Dutch. RRG analyzes the 'dative shift' phenomenon in the languages (and verbs) that allow it in terms of variable undergoer selection (Van Valin 2005: 61ff, Foley \& Van Valin 1985). Consider the following examples of macrorole assignment (adapted from Van Valin 2005: 46ff. \& 61). Example (8d) is the dative-shifted version of (8c):

(8) a. The ice melted.

BECOME melted' (ice)

b. Sara melted the ice.

[do' (Sara, Ø)] CAUSE [BECOME melted' (ice)] A

c. Pat gave the book to Chris.

[do' (Pat, Ø)] CAUSE [BECOME have' (Chris, book)] A NMR U

d. Pat gave Chris the book.

[do' (Pat, Ø)] CAUSE [BECOME have' (Chris, book)] A

U NMR

Macrorolehood and NMR-hood have important implications for the workings of the theory. The selection of the Privileged Syntactic Argument (PSA) - the closest RRG-equivalent to the notion of the traditional subject - is selected on the basis of the macrorole-status of the arguments in the logical structure. The macrorole assignment principles are summarized below (Van Valin 2005: 63).

(9) Default Macrorole Assignment Principles

a. Number: the number of macroroles a verb takes is less than or equal to the number of arguments in its logical structure.

1. If a verb has two or more arguments in its logical structure, it will take two macroroles;

2. If a verb has one argument in its logical structure, it will take one macrorole. 
b. Nature: for verbs which take one macrorole,

1. If the verb has an activity predicate in its logical structure, the macrorole is actor.

2. If the verb has no activity predicate in its logical structure, the macrorole is undergoer.

RRG distinguishes between syntactic transitivity (S-transitivity) and macrorole transitivity (M-transitivity). As macroroles have such a pivotal position within the theory, the concept of M-transitivity is the more important of the two. S-transitivity is an indication of the number of direct core arguments, whereas M-transitivity is an indication of the number of macroroles a verb takes (Van Valin 2005: 63-64). The importance of macroroles for the workings of RRG cannot be underestimated. Case marking and preposition assignment (Van Valin 2005: 107ff.), for instance, are tied to the macrorole-status of the argument in question. Dative case (in languages with a case system) is treated as the default case for NMRs, for example. Atypical case assignment is dealt with in terms of exceptional M-transitivity (Dahm-Draksic 1997, Van Valin 1991, Van Valin 2005). Semantic valence refers to the number of arguments in the logical structure. A table (adapted from Van Valin 2005: 64) comparing M-transitivity and semantic valence is given in table 8. Transitivity is always understood as M-transitivity in this book, unless otherwise specified. 


\begin{tabular}{|l|l|l|l|}
\hline $\begin{array}{l}\text { Semantic } \\
\text { valence }\end{array}$ & $\begin{array}{l}\text { Macrorole } \\
\text { number }\end{array}$ & $\begin{array}{l}\text { M- } \\
\text { transitivity }\end{array}$ & Example verb \\
\hline 0 & 0 & Atransitive & rain, snow \\
\hline 1 & 1 & Intransitive & die \\
\hline 1 or 2 & 1 & Intransitive & drink (activity) ${ }^{13}$ \\
\hline 2 & 2 & Transitive & $\begin{array}{l}\text { drink (active } \\
\text { accomplishment) }\end{array}$ \\
\hline 2 & 2 & Transitive & kill \\
\hline 3 & 2 & Transitive & set \\
\hline 3 & 2 & Transitive & send \\
\hline
\end{tabular}

Table 8: Transitivity in Role and Reference Grammar.

\subsubsection{Privileged Syntactic Argument}

Partly as a reaction to the problematic handling of ergative languages in terms of grammatical relations, RRG posits the so-called privileged syntactic argument of a construction (or: PSA). Van Valin points out that in all languages there are restrictions on the RPs and PPs that can feature in syntactic constructions. These restrictions are said to define a privileged syntagmatic function with respect to the construction (Van Valin 2005: 94). It is crucial to make clear that one cannot speak of 'the PSA in Dutch' or 'the PSA in English'. PSAs are constructionally defined (Van Valin 2005: 99). Therefore, there is no single PSA for a given language. Rather, English or Dutch have many PSAs, one per construction. All PSAs in one and the same language can be quite similar, however. It would be erroneous to treat the PSA as a notational variant of the term subject. 'Subject' is treated as a non-universal concept in RRG. The socalled S-function is considered to be a (restricted) neutralization of the actor and the undergoer of an intransitive verb. Simply put, if a language treats the actor-argument and the undergoer-argument of an intransitive verb the same way, then the language has an S-function. To illustrate: If a language treats fohn in fohn ran and in fohn died the same way, it has

13 If the second argument of activity verbs is non-referential, it does not take a macrorole. If it is referential, a second macrorole is assigned (Van Valin 2005: 64, also see Van Valin \& LaPolla 1997). 
an S-function. Languages like English, German and Dutch have such an S-function, but others, such as Acehnese, do not (Van Valin 2005: 96). In languages like Dutch and English the $S$, the actor of the transitive verb (Ат) and the 'derived subject' ${ }^{14}(\mathrm{~d}-\mathrm{S})$ are treated alike as PSA; they are 'restrictively neutralized'. In Acehnese, there is no such neutralization: Actor-PSAs are treated differently from undergoer-PSAs. Van Valin points out that besides the aforementioned S-function, languages are often very consistent in their treatment of PSAs across constructions. This high level of consistency in a given language can allow for positing a 'subject' as a kind of generalized PSA if most (or even all) of the major constructions in a language have the same pattern of restricted neutralization (Van Valin 2005: 99).

After the macroroles have been assigned to arguments in the logical structure by the application of the AUH, the PSA has to be assigned. The assignment of the PSA can be captured in terms of an accessibility hierarchy, which, in essence, is the actor half of the AUH (Van Valin 2005: 100):

$$
\begin{aligned}
& \text { Arg. of DO }>1 \text { st arg. of } \text { do' }^{\prime}>1 \text { st arg. of pred' }(x, y)>2^{\text {nd }} \\
& \text { arg. of pred' }(x, y)>\arg \text {. of pred' }(x)
\end{aligned}
$$

In accusatively-aligned languages, the highest-ranking direct core argument (in terms of (10)) becomes PSA. In ergatively-aligned languages, the lowest-ranking direct core argument becomes PSA. The hierarchy and the markedness of the choices - is thus inverse for ergativelyaligned languages. Principles for the default and marked assignment of the PSA can be now drawn up (Van Valin 2005: 100). These are given in table 9.

14 Crudely speaking, the subject of a passive. 


\begin{tabular}{|l|l|l|}
\hline Syntactic system & $\begin{array}{l}\text { Default choice for } \\
\text { PSA }\end{array}$ & $\begin{array}{l}\text { Choice for PSA } \\
\text { requiring special } \\
\text { construction }\end{array}$ \\
\hline Accusative & Actor & Undergoer [Passive] \\
\hline Ergative & Undergoer & Actor [Antipassive] \\
\hline
\end{tabular}

Table 9: PSA-assignment overview.

There is considerable cross-linguistic variation with respect to the PSA along three dimensions. First, there are languages that have variable PSAs. This means that not only the default choice for PSA is allowed, but also a marked choice (e.g. English and Dutch). Other languages (e.g. Lakhota) have fixed or invariable PSAs: they only have the default choice available to them. Roughly speaking, such languages do not have a passive (or antipassive in the case of ergative systems). Second, languages vary with respect to the required macrorole status for the PSA. Some languages only allow macrorole arguments as PSAs, whereas others also allow non-macrorole direct core arguments to function as PSA. German is an example of the former, Icelandic of the latter (Van Valin 2005: 100). However, oblique core arguments becoming PSA seem to be crosslinguistically strongly dispreferred (Van Valin 2005: 136, Van Valin 2009b). Third, some languages have case-sensitive PSAs (e.g. English and German). Others have case-insensitive PSAs (e.g. Belhare). Examples of PSA-assignment are given in (11).

(11) a. Pat gave the book to Chris. Default assignment [do' (Pat, Ø)] CAUSE [BECOME have' (Chris, book)] $\mathrm{A}+\mathrm{PSA}$ NMR U

b. The book was given to Chris by Pat. Marked assignment [do' (Pat, Ø)] CAUSE [BECOME have' (Chris, book)] A+ Peripheral PP NMR U+PSA

\subsubsection{The Linking Algorithm}

All of the aforementioned systemic devices come together in the linking algorithm, the centerpiece of RRG. The linking algorithm can be considered as a set of ordered rules that relate the semantics to the syntax, with 
discourse pragmatics playing an influential role (figure 1). The linking algorithm is considered bidirectional. It not only links semantics to syntax, but also maps a syntactic structure onto a semantic base through use of a parser. This 'reversed' linking occurs when language material is processed by the hearer. In other words, one direction captures language production, the other captures language comprehension (Van Valin 2005: 129). The RRG linking system is regulated by a general, overarching constraint, called the completeness constraint. It is given in (12).

(12) Completeness constraint (Van Valin 2005: 129-130)

All of the arguments explicitly specified in the semantic representation of a sentence must be realized syntactically in the sentence, and all of the referring expressions in the syntactic representation of a sentence must be linked to an argument position in a logical structure in the semantic representation of the sentence.

One can summarize the linking system as follows: The predicate comes with a certain logical structure. The semantic representation is built up out of these components in the lexicon. The semantic representation and the information therein determine the choice of syntactic templates (stored in the syntactic inventory). The syntactic template selection principle states that the number of arguments a verb takes must be equal to the number of positions that arguments can appear in (in the core). This can be considered a logical consequence of the completeness constraint. The syntactic template selection principle can be complemented by language-specific requirements, however. The syntactic template selection principle and language-specific qualifications (Van Valin 2005: 130) are given in (13).

\section{(13) Syntactic template selection principle}

The number of syntactic slots for arguments and argumentadjuncts within the core is equal to the number of distinct specified argument positions in the semantic representation of the core. 


\section{Language-specific qualifications}

1. All cores in the language have a minimum syntactic valence of 1 .

2. Argument-modulation voice constructions reduce the number of core slots by 1 .

3 . The occurrence of a syntactic argument in the pre/postcore slot reduces the number of core slots by 1 (may override 1. above).

Now that the main components of RRG's linking system have been introduced, the tenets of the theory presented in this chapter can be summarized as in figure 13.

Because the linking algorithm is bidirectional, two possible linking procedures can be spelled out. For my purposes, the semantics-to-syntax linking is by far the most important aspect. Therefore, only this direction of the algorithm is represented in (14) (adapted from Van Valin 2005: 123). It is important to stress that all the steps in the algorithm show cross-linguistic variation (for instance, variable undergoer selection or pragmatically influenced PSAs).

\section{Linking algorithm: semantics-to-syntax}

1. Construct the semantic representation of the sentence, based on the logical structure of the predicator.

2. Determine the actor and undergoer assignments, following the actor-undergoer hierarchy in figure 12 .

3. Determine the morphosyntactic coding of the arguments

a. Select the privileged syntactic argument, based on the privileged syntactic argument selection hierarchy and respective principles.

b. Assign the arguments the appropriate case markers and/or adpositions.

c. Assign the agreement marking to the main or auxiliary verb, as appropriate. 
4. Select the syntactic template(s) for the sentence following the appropriate principles.

5. Assign arguments to positions in the syntactic representation of the sentence.

a. Assign the $[-\mathrm{WH}]$ argument(s) to the appropriate positions in the clause.

b. If there is a $[+\mathrm{WH}]$ argument of a logical structure,

1. assign it to the normal position of a non-WH-argument with the samefunction, or

2. assign it to the precore or postcore slot, or

3. assign it to a position within the potential focus domain of the clause (default $=$ the unmarked focus position).

c. A non-WH argument may be assigned to the precore or postcore slot, subject to focus structure restrictions (optional).

d. Assign the [-WH] argument(s) of logical structure(s) other than that of the predicator in the nucleus to

1. a periphery (default), or

2. the precore or postcore slot, or

3. the left- or right-detached position.

It is crucial to bear in mind that everything discussed so far applies to simple sentences. Even though matters are obviously more complicated in complex sentences, the same basic principles apply. It is possible to graphically represent the linking in its various stages. The representation of figure 2 is given in figure 14, including the logical structure and the various stages of linking from semantics to syntax. 


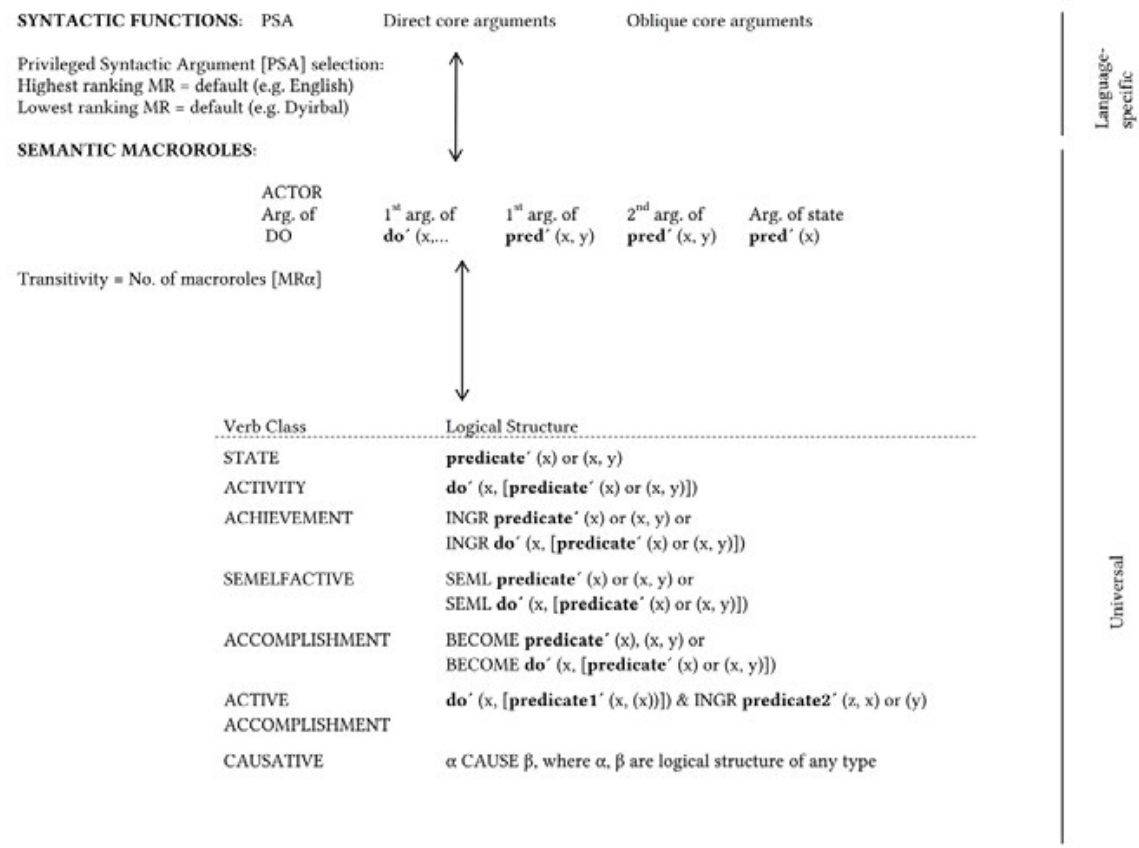

Figure 13: General overview and summary of the RRG linking system (Van Valin 2005: 129).

Figure 14 is a visualization of the linking algorithm using the sentence from figure 2 as an example (adapted from Van Valin 2005: 140). The steps in the linking are indicated in the circles and correspond to the phases of linking described in (14). 


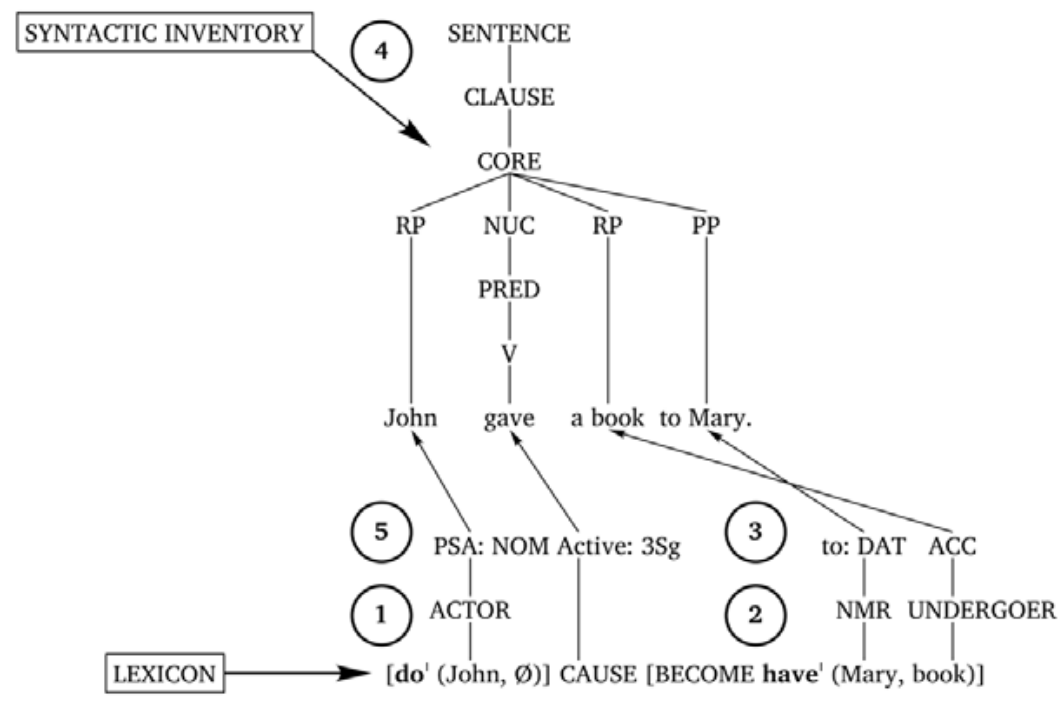

Figure 14: Semantics-to-syntax linking in its successive steps.

\subsection{Conclusion}

In this chapter, I have introduced the basic tenets and principles of Role and Reference Grammar. I have discussed the fundamentals of the theory, its general organization and single components. We have seen that the Layered Structure of the Clause and its phrase-level equivalent are versatile concepts capable of capturing a wide range of language phenomena without resorting to transformations, movement or similar devices. RRG makes extensive use of its GSRs actor and undergoer. PSAassignment and case assignment (Van Valin 2009b and 2005: 107ff.) are tied to them, for example. This brief exploration of RRG applies primarily to simple sentences. With the information presented in this chapter, it is possible to refine the organizational figure in 1 into the one in 15 (Van Valin 2005: 134) by adding several important mechanisms that were discussed in this chapter. 


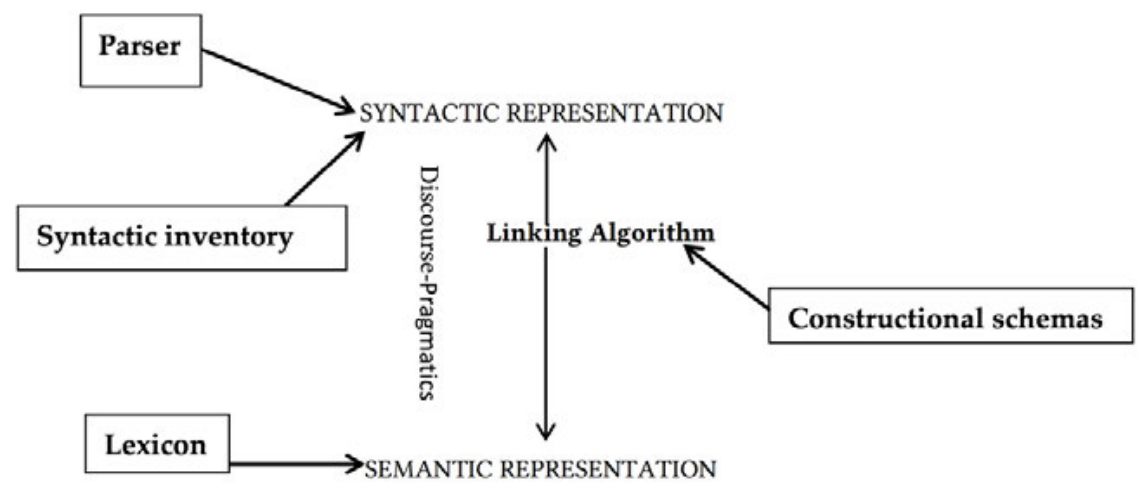

Figure 15: General organization of Role and Reference Grammar (final).

Case and preposition assignment in RRG were not discussed in this chapter. They are, however, very relevant for the topic of this dissertation. They will be introduced in chapter 8 where the linking of instruments to the morphosyntax is explored. 